\title{
Pandemia é pandemia em qualquer lugar - vivendo a crise da Covid-19 de fora dos grandes centros
}

La pandemia es pandemia en cualquier lugar: viviendo la crisis de Covid-19 desde fuera de los principales centros

Une pandémie est une pandémie, peu importe le lieu : en vivant la crise de la Covid-19 à la marge des grands centres

Pandemic is pandemic anywhere - living the Covid-19 crisis from outside the major centers

\section{Tatiana Tramontani Ramos}

\section{CpenEdition} Journals

Edição electrónica

URL: http://journals.openedition.org/espacoeconomia/11406

DOI: 10.4000/espacoeconomia.11406

ISSN: 2317-7837

Editora

Núcleo de Pesquisa Espaço \& Economia

Refêrencia eletrónica

Tatiana Tramontani Ramos, « Pandemia é pandemia em qualquer lugar - vivendo a crise da Covid-19 de fora dos grandes centros », Espaço e Economia [Online], 18| 2020, posto online no dia 17 abril 2020, consultado o 20 maio 2020. URL : http://journals.openedition.org/espacoeconomia/11406 ; DOI : https://doi.org/10.4000/espacoeconomia.11406

Este documento foi criado de forma automática no dia 20 maio 2020.

(c) NUPEE 


\title{
Pandemia é pandemia em qualquer lugar - vivendo a crise da Covid-19 de fora dos grandes centros
}

\author{
La pandemia es pandemia en cualquier lugar: viviendo la crisis de Covid-19 \\ desde fuera de los principales centros \\ Une pandémie est une pandémie, peu importe le lieu : en vivant la crise de la \\ Covid-19 à la marge des grands centres \\ Pandemic is pandemic anywhere - living the Covid-19 crisis from outside the \\ major centers
}

Tatiana Tramontani Ramos

1 Iniciamos com a paráfrase da letra dos Racionais MCs "periferia é periferia em qualquer lugar" como proposta de reflexão escalar para o tipo de fenômeno que estamos a vivenciar. Ainda estamos em processo, não amadurecemos as condicionantes, muito menos as consequências. Escrever sobre processos em curso, especialmente de tamanha dimensão, é sempre problemático por ser incompleto e passível de muitas análises equivocadas. Mas é um risco que escolhemos correr também como escape analítico para algo que ainda não elaboramos e, na verdade, nem sabemos como. Encerrado esse texto aos quatro dias do mês de abril, contaremos com a condescendência dos leitores para todas as suas inconsistências.

$* * *$

3 Com vinte dias de isolamento social, popularmente nomeado de quarentena no Brasil de 2020 - a despeito de nem todos estarem cumprindo isolamento imposto por exposição direta, ou contágio, como o nome sugere - vivemos ainda uma rotina provisória, um cotidiano bastante atípico e um horizonte em suspenso, como boa parte da humanidade está a experimentar.

4 A experiência do isolamento em uma grande metrópole talvez traga impactos mais evidentes do distanciamento e da pausa. As ruas vazias e o (quase) silêncio podem ser 
mais impressionantes quando se trata de São Paulo, Roma, Nova Iorque. Mas a experiência de estar em isolamento em uma cidade do interior, com as diferentes conotações que o interior possa ter em um país como o Brasil é, também, exótica ao nosso comportamento natural, aos encontros da lentidão e ao calor da nossa cultura, em todos os aspectos que, de uma forma ou de outra, tocam a vida de sujeitos urbanos ao redor do mundo. Romper com a natureza sócio-geográfica da urbanidade tem sido desafiador, porque rompemos com

[...] o caráter aglutinador do urbano. 0 urbano, entendido como um produto sócioespacial, possui uma força aglutinadora, como podemos observar em relação ao processo de industrialização e urbanização. 0 urbano aglutina pessoas, capital, instituições financeiras, indústrias, comércio, meios de produção, casas, portos, museus, centros administrativos, órgãos do Estado, empresas, sindicatos, etc. 0 urbano concentra as instituições políticas, econômicas e culturais que se colocam como hegemônicas na sua relação com outros grupos/classes sociais (trabalhadores, camponeses, oligarquias rurais, pobres urbanos, etc.); é o lugar dos centros de decisões, de onde parte o controle da produção, as decisões políticas, de produção de subjetividade (produção de desejos, necessidades e símbolos hegemônicos), produção de modas e culturas de massa. Ao mesmo tempo o urbano é o lugar do encontro entre as pessoas, encontro das diferenças, das festas, das culturas populares, das práticas de resistência ao poder hegemônico que se dá nos corpos, no tempo e no espaço. (RAMOS, 2003:18)

Abastecer-se, trabalhar, divertir-se, estudar, atividades corriqueiras mediadas pelo deslocamento que define o ser-estar urbano, interditadas por uma nova geografia que se impõe sobre a nossa relação espaço-tempo. Além disso, o urbano carrega consigo dois aspectos fundamentais para a compreensão do impacto de uma pandemia e de medidas para a tentativa de controle - como as medidas de isolamento e paralização de atividades - que são a experiência do trabalho e experiência do morar/habitar a cidade. Em ambos aspectos, a cidade é um locus excepcional para se pensar o isolamento e suas consequências. E sendo mais da metade da população mundial atual urbana ${ }^{1}$, refletir sobre o trabalho e sobre o habitar nas cidades passa a ser urgente.

Invariavelmente e em diferentes escalas, o mundo do trabalho será profundamente impactado pela pandemia, assim como as diferenças na infraestrutura urbana e seus níveis de segregação, desigualdade e desenvolvimento sócio-espacial farão toda diferença nas consequências desse momento histórico no futuro das cidades. $O$ processo ainda está em curso. A periferia do sistema capitalista adentra agora ao estado de urgência/calamidade. As consequências ainda são incertas e especulativas, mas os prognósticos, assustadores, como vêm sinalizando alguns documentos e estudos técnicos ao redor do mundo.

7 E não se trata de reducionismo economicista quando falamos em trabalho e renda, ou nos impactos da desigualdade quando tentamos ajustar lentes para avaliar e analisar o estado de pandemia. Implica refletir sobre as relações de poder que atravessam

os discursos legitimadores das práticas, as instituições estatais e privadas, as formas de regulação e controle dos corpos e do território, a gestão, apropriação e predação da natureza, enfim, uma série de elementos que não são redutíveis à análise econômica. (RAMOS, 2003:19)

Definir a urbanidade é, necessariamente, entender que a mediação e o referencial de praticamente todas as relações humanas, da cultura e lazer, à alimentação e habitação, é o dinheiro. E o dinheiro, para a maioria das pessoas, é obtido pela venda da força de trabalho na forma do trabalho assalariado, ou pela acumulação de capital pelos 
detentores dos meios de produção via extração de mais valia, para a minoria. Mas também em diferentes frações e variações, maiores e menores, dessas duas primeiras. Empresários e profissionais liberais, trabalhadores informais, precarizados e hiperprecarizados.

9 Falar do urbano, quase sempre, é falar da impossibilidade de se viver exclusivamente do seu trabalho, de forma independente de outras relações de produção e trabalho, como acontece com pequenos produtores no campo, por exemplo. Consequentemente, interromper fluxos, encontros, contatos, relações, é interromper o que define o trabalho nas cidades. E isso tem consequências. Que não são definitivas, mas com potencial para grandes estragos. E que não seriam tão graves, se não fosse em um sistema tão injusto e excludente.

10 Ao mesmo tempo, a outra dimensão, ou segundo elemento fundamental da compreensão do urbano, o morar-habitar, também implica refletir sobre o tipo de vida que se constrói fora de casa, além de dentro dela. Também implica entender a totalidade de uma sociedade extremamente desigual na forma como materialmente se apropria da cidade como abrigo.

11 A segregação e a precariedade dos espaços segregados será um marco para a compreensão dos impactos da pandemia da Covid-19 na periferia do capitalismo e as cidades, mais uma vez na história, serão um grande laboratório dessa experiência, em diferentes extensões, dimensões e durações. E obviamente, a questão da dimensão/ extensão desse processo é variável de destaque nessa análise. 0 urbano metropolitano estará implicado de forma muito mais complexa por qualquer um dos dois pontos levantados, trabalho e moradia/habitação, do que o urbano não-metropolitano.

Tentaremos trazer um pouco dessa reflexão a partir de um centro regional, uma cidade média do interior do estado do Rio de Janeiro, onde as peculiaridades do interior se misturam e, algumas vezes, se chocam, com algumas simetrias com os grandes centros urbanos do país. A dimensão da segregação urbana já é parte da realidade do Norte Fluminense, em Macaé, Campos dos Goytacazes e há muito tempo. Extensas áreas favelizadas, condomínios horizontais de habitação popular de baixa renda proliferaram nas últimas décadas. Condomínios esses deslocados dos centros e dotados de pouca infraestrutura além de arruamento e unidades habitacionais padronizadas, escassas opções de mobilidade/acessibilidade, bem como de equipamentos de lazer, educação e saúde, com o agravante de, na maioria das vezes, serem dotados de unidades habitacionais de tamanho e estrutura inadequada para o número de moradores².

13 Apesar de não termos na realidade local-regional, a representatividade numérica de famílias em situação de grande vulnerabilidade social, como as grandes cidades, a apreensão com a possibilidade de disseminação da Covid-19 entre a população mais vulnerável é extremamente grande, pois a insuficiência e inadequação do sistema de saúde se faz mais notável.

o município apresenta um índice aproximado de 3,2 leitos a cada mil habitantes, acima da média ideal proposta pelo Ministério da Saúde $(2,5)$ e dentro do mínimo estipulado pela Organização Mundial da Saúde (3 a 5 leitos por mil habitantes). A partir dos dados do IBGE, relativos a 2010, a rede é constituída por 88 estabelecimentos privados, 87 municipais, 1 estadual e nenhum federal, sendo que do total de leitos disponíveis (1.646), a maioria encontra-se na rede privada (1.446), (...). Os leitos de estabelecimentos públicos são em número de $200^{3}$. 
Em Campos, por exemplo, a proliferação de casos entre a população de mais baixa renda tem potencial para causar o colapso da saúde local. Até o dia 04/04 havia dezesseis casos confirmados no N.F., três em Campos dos Goytacazes, treze em Macaé e dezenas de casos suspeitos. A principal preocupação quanto às suspeitas é aquela que se repete pelo país, a atual ausência de testes e a demora nas respostas àqueles que foram realizados, analisados fora da cidade ${ }^{4}$.

Desde o dia 16 de março de 2020 as Prefeituras de vários municípios do Norte Fluminense vêm adotando medidas em sintonia com as orientações do Governo do Estado e da Organização Mundial de Saúde, com suspensão de aulas na rede básica e superior de ensino, fechamento do comércio e prestação de serviços considerados não essenciais, suspensão de eventos presenciais de qualquer ordem, além de redução na circulação do transporte público.

O interior do estado do Rio de Janeiro conta predominantemente com uma economia de base primária em sua essência mineral-energética (gás, óleo e cana-de-açúcar), e terciária em sua aparência, característica típicas de inúmeros municípios que desde muito tempo vêm repisando em escala reduzida a história do Brasil. O volume de movimentação oriundo de uma economia primário-exportadora e a dinâmica econômica da escala trabalho apontam para a boa e velha desigualdade na simultaneidade, característica de um circuito superior integrado à escala internacional ao qual se somam um circuito intermediário e um circuito inferior não menos importantes à sobrevivência do local. Em outras palavras, trabalhadores altamente qualificados e articulados às redes nacionais e internacionais de contratação, deslocamento e cosnumo, convivem, se relacionam e, no limite, dependem alimentação, hospedagem, deslocamento etc. - com toda sorte de formas de trabalhos corriqueiras e também aquelas subnormais, como aquelas extremamente precárias e territorialmente instáveis.

Uma região que cresce ao ritmo e imposições do mercado internacional e das macropolíticas econômicas - para setores como o logístico e mineral-energético, por exemplo - o Norte Fluminense e, mais especificamente, Campos dos Goytacazes, Macaé e São João da Barra, com maior destaque, sobrevivem internamente de uma dinâmica econômica muito doméstica e que reflete, por isso, questões típicas de um Brasil ainda profundamente arraigado aos seu passado colonial. Exploração da mão-de-obra, racismo estrutural, segregação sócio-espacial, baixa escolarização e altíssima informalidade são a tônica de nosso "desenvolvimento humano".

18 A existência de megaprojetos de infraestrutura, como o Complexo Industrial Logístico Porto do Açu (CLIP Açu, em São João da Barra/RJ), bem como a economia petrolífera e o complexo sucro-alcoolero - hoje bem menos representativo na economia regional, mas não menos tradicional e ainda relevante - ressaltam um passado e a presença de uma economia de drenagem, profundamente vinculada aos mercados externos, não dispensa a existência de uma extensa economia paroquial, de varejo, formal e informal, que segue subsidiando a vida dos comuns.

19 E eis a nossa distopia particular e nosso microcosmo do caos. A pandemia entra pela "porta da frente", como de fato vem acontecendo em tantas cidades do Brasil, desembarca nos aeroportos (em voos comerciais e presidenciais), nos portos com navios de passageiros e de carga, se dissemina a partir dos "andares de cima", mas não poupa, por isso, os "andares de baixo". 
20 Ao mesmo tempo que os trabalhadores mais expostos, em um primeiro momento, são aqueles que mais circulam entre os municípios citados e os grandes centros do país, ou que estão envolvidos diretamente em atividades com tais pessoas, o potencial para a transmissão comunitária do vírus é enorme na medida em que atividade e funções de demanda estritamente local e regional se somam ao estímulo dos grandes projetos e empreendimentos. Tanto no que tange a Petrobrás (mais as subcontratadas e outras empresas licenciadas no mercado petrolífero onshore e offshore), quanto o Complexo Logístico Industrial do Porto do Açu, houve uma adesão dessas grandes empresas à paralisação de muitas atividades, ou ao menos, redução do ritmo e número de trabalhadores envolvidos, o que automaticamente impacta na demanda pelos serviços citados e impõe uma severa pena às economias locais. Sem mencionar todo o efeito em cadeia que isso ocasiona no comércio e serviços em demais atividades.

Em entrevista concedida por escrito com o diretor executivo do Sindicato dos Petroleiros do Norte Fluminense no dia 25/03/2020, o representante dos trabalhadores do setor expôs um pouco de como a pandemia decretada mundialmente e reafirmada no Brasil tem trazido reflexos para a atividade petrolífera na região: "os helicópteros estão indo para as plataformas vazios e voltando para terra cheios", afirma.

Muitos dos trabalhadores que atuam nas plataformas - mais de trinta na bacia de Campos - deslocam-se de outras municípios e outros estados para trabalhar. Esta é uma rotina bastante comum no Norte Fluminense, mas especialmente em Campos dos Goytacazes e Macaé, cidades que são bases para o embarque e desembarque nas plataformas por seus aeroportos e pelo heliporto de Farol de São Tomé (distrito de Campos) e que tem sido denunciada pelo sindicato como imprudente na atual conjuntura.

Existem muitos trabalhadores de outros estados, em torno de $40 \%$, e muitos não estão conseguindo chegar devido o fechamento dos aeroportos, cancelamentos de voos, cancelamento de linhas intermunicipais e interestaduais [de ônibus]. Muitos estão tendo muita dificuldade de voltar para casa e estamos cobrando da Petrobras que ela se responsabilize por esse retorno aos próprios e terceiros.

23 Segundo o diretor do Sindipetro-NF, tem havido nos últimos dias uma subnotificação dos casos em função da falta de suporte da própria Petrobrás aos trabalhadores, tanto àqueles que se encontram embarcados ${ }^{5}$, quanto àqueles que estão em terra, deslocandose para efetuar o embarque.

Todos os casos suspeitos nas plataformas estão sendo desembarcados e não estão entrando nas estatísticas das cidades da Região. (...) Infelizmente a Petrobrás não age com transparência e todos os trabalhadores desembarcados com suspeita não estão sendo passadas as informações sobre o diagnóstico médico pós desembarque, mas aparentemente ainda não temos caso de contágio entre os trabalhadores próprios e terceiros da Petrobras no NF. (T. Bezerra, 25/03/2020)

24 Apesar de ter reduzido o volume de embarques após as medidas decorrentes da pandemia terem sido adotadas no Brasil, e de ter adotado uma espécie de quarentena reduzida, de sete dias, imposta aos trabalhadores que chegam à Campos, Farol e Macaé para o embarque em hotéis e pousadas locais, ainda existe muita apreensão quanto ao impacto da grande circulação de pessoas que a atividade impõe em diferentes escalas e condições sanitárias.

Motoristas de vans e micro-ônibus, os serviços de lavanderia, bares e restaurantes, pousadas e pequenos hotéis, prestadores de serviços domésticos diversos, são uma primeira grande cadeia de vulnerabilidade e também de disseminação local, pelo tipo 
de contato que o trabalho exige. Há denúncias dos trabalhadores ao sindicato dos petroleiros, ainda, de deslocamentos sendo feitos por períodos de até quatro horas (Campos-Rio de Janeiro) em vans fretadas com lotação máxima levando trabalhadores para as cidades de embarque.

Ainda é cedo para afirmar, mas é possível imaginar uma parcela considerável de responsabilidade da Petrobrás e parceiras nas atividades no Norte Fluminense nos casos de contaminação que virão ser registrados nos municípios da região.

O mesmo tem sido apontado entre os trabalhadores do grande empreendimento de logística e infraestrutura portuária local, o Complexo do Açu. Obtivemos alguns dados recentes em entrevista realizada pela mestranda Nina Barreto para sua pesquisa sobre o Porto com trabalhadores da Andrade Gutierrez e da Acciona, empresas do ramo da construção civil, infraestrutura e energia. Um dos trabalhadores que atua no CLIP Açu relatou que as empresas que atuam no complexo deram férias coletivas para 3,5 mil trabalhadores, restando um numero muito reduzido para lidarem com maquinários que precisam de manutenção permanente. Informação confirmada no noticiário ${ }^{6}$ local.

A diferença da dinâmica de trabalho do complexo portuário, para o ramo petroleiro, entre inúmeras especificidades próprias as atividades, é claro, é o tipo de territorialização e deslocamento dos funcionários. Enquanto as plataformas funcionam por regime de escala de embarque e desembarque e esses períodos duram semanas, a maioria das atividades do CLIP Açu impõe jornadas de trabalho com escalas diárias, onde trabalhadores retornam à casa diariamente. Neste caso, guardando-se as recomendações de minimizar encontros presenciais, evitar aglomerações e reduzir a circulação de pessoas, a contribuição para a transmissão local será reduzida.

29 Ainda que o comportamento do vírus e sua disseminação ainda sejam incógnitas nos países da América e da África, especialmente em áreas periféricas, adensadas e precárias de muitos países, esta já é uma preocupação colocada em pauta, dado o histórico de endemias, doenças tropicais e aquelas ligadas à má nutrição, falta de saneamento básico entre outros problemas. Áreas em que as medidas de isolamento, não-aglomeração, cuidados de higiene pessoal e com os alimentos são muito mais difíceis de serem seguidas. Essa não é uma realidade alheia a Campos e ao interior do estado do Rio de Janeiro. Por mais que, em números absolutos, a população mais vulnerável neste sentido seja reduzida em relação às metrópoles.

Medidas de restrição, isolamento e interrupção de atividades, como em outras cidades e estados do país, têm afetado diretamente a rotina habitual das cidades e, além disso, têm impactado diretamente na economia local. Por mais que haja uma forte resistência de comerciantes locais ao fechamento das lojas e até insatisfação com as medidas de suspensão de aulas na rede básica de ensino (particular e pública) estas acabam sendo particularmente mais nocivas aos trabalhadores de baixa renda e aqueles que atuam informalmente, como prestadores de serviço, ambulantes e os chamados "autônomos".

31 O trabalho se tornou objeto de reflexão central quando se fala na pandemia da Covid-19. Trabalho remoto, ensino à distância, serviços de entrega em geral com tendência de aumento... mas a cultura do trabalho assalariado, e mesmo a naturalização do trabalho precário são incompatíveis com a subsistência em caso de interrupção de atividades, ainda que por um período relativamente determinado, como salientou recentemente Emiliano Mantovani,

Si hemos dicho que el encierro, la cuarentena, es una necesidad, al mismo tiempo esta es socialmente insostenible en el tiempo. Para los miles de millones de 
precarizados del mundo, es inmediatamente inviable. Para otros, representa una parálisis de anhelos, sociabilidades, descontentos, proyectos. (MANTOVANI, 2020:08) mencionado, repisa há séculos um histórico dos grandes flagelos que definem a história do Brasil, que vão da intensa desigualdade social e racial, até um histórico de clientelismo político e assistencialismo marcado por corrupção endêmica, a probabilidade de que a pandemia seja mais cruel para os pobres já figura como um temor, assim como nas granes metrópoles do país. Já havíamos sinalizado em trabalho anterior que, segundo dados do IDH-M (2010) percentual de pobres e muito pobres em Campos se aproximava dos $20 \%$,

o que significa quase um quinto da população do município vivendo com menos de 140 Reais (pobres), ou 70 Reais (extremamente pobres) per capita/mês. A renda per capita no município em 2010 era de cerca de um salário mínimo, apesar da receita municipal per capita ultrapassar os 5 mil reais. Esses dados invariavelmente se materializam no espaço urbano de Campos dos Goytacazes através da segregação sócio-espacial e, também, da autossegregação. (RAMOS, 2016:09)

Situação que não mudou nos últimos anos e, ao contrário, tem se agravado, com o aumento do desemprego e da violência urbana.

A pandemia, seja no centro, seja na periferia do capitalismo, em múltiplas escalas, do bairro em que muros de condomínios exclusivos ladeiam extensas favelas; às metrópoles com sua pobreza visível e invisível materializada entre outras formas na população em situação de rua e no trabalho hiperprecário, expõe nossas assimetrias históricas e o surto vai expor nossas entranhas.

Não será "só" o desemprego, a incapacidade de gerar a própria subsistência, o grande choque. Será, também, a demarcação entre quem vive e quem morre, quem tem como e onde se "proteger" e quem simplesmente não tem.

Aqueles com bons planos de saúde que também podem trabalhar ou ensinar de casa estão confortavelmente isolados, desde que sigam salvaguardas prudentes. Os funcionários públicos e outros grupos de trabalhadores sindicalizados com cobertura decente terão de fazer escolhas difíceis entre renda e proteção. Enquanto isso, milhões de trabalhadores com baixos salários, trabalhadores rurais, desempregados e sem teto estão sendo jogados aos lobos. (DAVIS, 2020:09)

Repensar o trabalho, o emprego, as necessidades e o consumo será um dos grandes legados da Pandemia de 2020. Entender os limites de uma economia baseada na superexploração do trabalho, na extração extrema de mais-valia e no individualismo é uma oportunidade inaugurada pelo caos.

Nunca parecía estar tan a la mano una oportunidad de despliegue de la otredad de esas lógicas y ritmos diferentes a los del sistema capitalista. La centralidad, ante los desafíos que representa esta paradoja colapso/oportunidad, parece estar en una política de lo común, del cuidado, de la reproducción de la vida, ante este capitalismo que se va quedando al desnudo. Ese camino se há abierto ante nosotros, sin que eso necessariamente represente uma garantía de éxito. (MANTOVANI, 2020:09) eixos da cidade de Campos para, superficialmente, avaliar o impacto das medidas de isolamento na circulação de pessoas e algumas questões são dignas de nota.

O que temos observado nas três últimas semanas tem sido uma redução significativa no movimento de carros e pedestres em áreas de comércio de rua e movimento de 
pedestres, dada a imposição da suspensão de atividades ao comércio varejista e serviços não essenciais pela Prefeitura desde o dia 16/03/20 (não sem protesto de muitos comerciantes $\left.{ }^{7}\right)$. No entanto, ainda é perceptível o persistente movimento de trabalhadores e trabalhadoras nos horários de pico (início da manhã e final da tarde), de uniforme ${ }^{8}$, ou não, portando mochilas e bolsas a tiracolo, em sua maioria deslocando-se sozinhos(as). Este movimento é notável em um dos principais eixos viários da cidade, a Av. 28 de Março (BR-356) que é dotada de uma ciclovia muito utilizada como eixo de transporte por trabalhadores "não motorizados". 0 trabalho, para muitos, não parou.

El confinamiento social de la cuarentena, pero también las calles vacías o semidesiertas, los mercados truncados, el confinamiento de los más pobres a una extraña precarización socio-económica ralentizada, nos abren el camino hacia otras temporalidades, otros ritmos, otras sociabilidades, otras apreciaciones y sensibilidades. (MANTOVANI, 2020:09)

É possível perceber trabalhadores nos pontos de ônibus e vans, pois para muitos, perversamente, o deslocar-se e o não se isolar não é uma escolha. Os pontos e os veículos têm mais pessoas do que o desejado, mulheres e homens, negros em sua maioria. Outra observação digna de nota é o grande número de motociclistas fazendo entregas por aplicativos que facilmente se identificam pelas caixas-mochilas.

Alguns podem dizer que a quarentena, ou isolamento social, como se queira nomear, é um privilégio de classe. Preferimos defender que se trata de um direito roubado de muitos trabalhadores e trabalhadoras, já que o privilégio coloca o direito numa posição de exceção. Proteger-se, estar seguro em casa, não se expor ao contato social em situação de pouca segurança e muito risco não deveria ser tratado como privilégio, mas um direito assegurado a todos e todas. Não é o que temos visto em Campos dos Goytacazes. Provavelmente não será a regra em outras cidades médias e grandes, do Brasil e do mundo.

41 Se a percepção da duração e da extensão já se mostra diferente em se tratando de compararmos o urbano metropolitano ao urbano não-metropolitano, médio, pequeno, interior, o isolamento, de certo modo, aproximou as duas pontas desta percepção. Hoje somos muito mais convidados a ressignificar tempo-espaço a partir da escala da casa, da rede doméstica de relacionamento face-a-face e redimensionar os impactos de uma produção-trabalho limitada justamente por tais imposições.

Seguimos em isolamento. Seguimos acreditando que que é o melhor a ser feito por quem não pode fazê-lo. Seguimos acreditando na ciência e nas experiências prévias em situações de risco e de grandes epidemias. Seguimos acreditando no potencial de transformação social da pandemia, aqui e em todo lugar.

\section{BIBLIOGRAFIA}

DAVIS, Mike. "A crise do coronavírus é um monstro alimentado pelo capitalismo”. In DAVIS, Mike et. Al. Coronavírus e a luta de classes. Terra sem Amos: Brasil, 2020. 
MANTOVANI, Emiliano T. El Coronavirus más allá del Coronavirus: umbrales, biopolítica y emergências. Publicado em 19/03/2020 e disponível em https://kaosenlared.net/el-coronavirusmas-alla-del-coronavirus-umbrales-biopolitica-y-emergencias/, acesso 02/04/2020.

RAMOS, Tatiana Tramontani. "A geografia dos conflictos sociais da América Latina e Caribe”. Informe final del concurso: Movimientos sociales y nuevos conflictos en América Latina y el Caribe. Programa Regional de Becas CLACSO. 2003 Disponible en la World Wide Web: http:// bibliotecavirtual.clacso.org.ar/ar/libros/becas/2002/mov/tramon.pdf "Crescimento econômico e desenvolvimento sócio-espacial em Campos dos Goytacazes". GeoUERJ, Rio de Janeiro, n. 29, p. 63-88, 2016. doi:10.12957/geouerj.2016.16109.

\section{NOTAS}

1. Com todas as relativizações que essa estatística possa conter em diferentes contextos territoriais.

2. Em Campos esses condomínios são parte do Programa de Habitação Municipal chamado Morar Feliz, que consistem em 18 condomínios horizontais e mais de 32 mil pessoas; mas também conta com dois condomínios oriundos do Programa Minha Casa Minha Vida, do governo federal.

3. É provável que esses números já tenham sido alterados, no entanto, não sofreram atualizações oficiais dede o levantamento de 2010. Alguns estabelecimentos privados citados são conveniados ao SUS. Disponível em https://cidades.ibge.gov.br/brasil/rj/campos-dos-goytacazes/pesquisa/ 32/0. Acesso em 04/04/2020.

4. Segundo a prefeitura, os laudos saem do Laboratório Central Noel Nutels (LACEN-RJ).

5. Os petroleiros, tanto da Petrobrás, quanto os terceirizados, cumprem escalas de trabalho que costumam seguir a rotina de 14 por 21, ou seja, 14 dias em terra, para 21 dias embarcados.

6. Jornal Terceira Via - https://www.jornalterceiravia.com.br/2020/03/20/empresa-do-porto-doacu-concede-ferias-coletivas-a-funcionarios-devido-a-coronavirus/. Acesso em 30/03/2020.

7. Haja vista a adesão ao movimento de "carreatas pela reabertura do comércio" divulgada e estimulada pelo presidente da república no dia 27/03/2020, com alguma adesão local https:// g1.globo.com/rj/norte-fluminense/noticia/2020/03/27/autoridades-se-reunem-apos-carreatade-comerciantes-em-campos-rj-nenhuma-medida-sera-suspensa.ghtml, acesso em 31/03/2020.

8. Foram observados alguns trabalhadores do Porto do Açu, que se destacam pelo uso do macacão com identificação das empresas em que atuam.

9. Uma característica muito importante da mobilidade urbana em Campos dos Goytacazes, tanto por parte de trabalhadores de baixa renda, quanto por estudantes universitários é o transporte por bicicletas, nem sempre por ciclovias, que denota uma dificuldade de arcar com o alto custo do transporte público (hoje 2,75 em qualquer linha de ônibus ou van do município) e sua precariedade e insuficiência de linhas e carros.

\section{RESUMOS}

Buscaremos analisar, ainda que provisoriamente, dado o decorrer dos fatos e processos, a experiência do isolamento em um centro regional, estabelecendo pontes com a dinâmica das 
grandes metrópoles. Especulamos que em diferentes escalas, o mundo do trabalho será profundamente impactado pela pandemia, assim como as diferenças na infraestrutura urbana e seus níveis de segregação, desigualdade e desenvolvimento sócio-espacial farão toda diferença nas consequências desse momento histórico para o futuro das cidades. A periferia da periferia capitalista adentra agora ao estado de urgência/calamidade. As consequências ainda são incertas, os prognósticos, assustadores, o convite a ressignificar tempo-espaço, relacionamento face-a-face e a produção-trabalho passam a ser urgentes.

Intentaremos analizar, aunque de manera provisional, dados los hechos y procesos, la experiencia del aislamiento en un centro regional, estableciendo puentes con la dinámica de las grandes metrópolis. Especulamos que en diferentes escalas, el mundo del trabajo se verá profundamente impactado por la pandemia, así como las diferencias en la infraestructura urbana y sus niveles de segregación, desigualdad y desarrollo socioespacial marcarán la diferencia en las consecuencias de este momento histórico para el futuro de las ciudades. La periferia de la periferia capitalista ahora entra en el estado de urgencia / calamidad. Por lo tanto, las consecuencias aún son inciertas y los pronósticos son aterradores. Por esta razón, la invitación a replantear el espacio-tiempo, la relación cara a cara y el trabajo de producción, en efecto, hacerse urgente

On cherche à analyser (et encore de façon provisoire) l'expérience de l'isolement dans un centre régional mais sans oublier les connexions avec les grandes métropoles. On conjecture que le monde du travail sera profondément impacté par la pandémie en plusieurs échelles, et que les niveaux d'infrastructure urbaine, de ségrégation, d'inégalité et de développement socio-spatial vont faire la différence par rapport l'avenir des villes. Pour l'instant, la périphérie de la périphérie capitaliste vive un moment de calamité publique. Les conséquences sont encore incertaines et les pronostics effrayantes, mais le besoin de ressignifier l'espace-temps, les rapports face-à-face et le pair production-travail est devenu urgent.

Writing in the heat of our indignation, this article analyses the quarantine experience from the interior of the Rio de Janeiro state, but without forget the relations with metropolitan dynamics. We believe that the urban levels of infrastructure, segregation, inequality and socio-spatial development will make the difference during and after the crisis. Despite the world of labor will be deeply impacted in different scales, the periphery of the periphery now enters into a stage of urgency. Consequences and prognoses are as uncertain as terrifying, but the need of rethinking time and space, face to face relationships, and the pair production and work become crucial.

\section{ÍNDICE}

Mots-clés: pandémie, périphérie, travail, ségrégation, urbain.

Palabras claves: pandemia; periferia trabajo segregación urbano

Palavras-chave: pandemia; periferia; trabalho; segregação; urbano.

Keywords: pandemic; periphery; labour; segregation; urban geography.

\section{AUTOR}

\section{TATIANA TRAMONTANI RAMOS}

UFF-Campos dos Goytacazes, Programa de Pós-Graduação em Geogafia, Núcleo de Estudos sobre Território e Conflitos Sociais. Email : tatiana_tramontani@id.uff.br 